\title{
DINÂMICAS EDUCATIVAS JUNTO À EQUIPE DE ENFERMAGEM SOB A PERSPECTIVA CULTURAL DE CUIDADO À PUÉRPERA
}

\author{
[Educational dynamics with the nursing staff under a cultural care focus on mothers at puerperium]
}

Vanessa Munhoz de Oliveira Krüger* Ivete Palmira Sanson Zagonel **

RESUMO: Este trabalho foi realizado em uma instituição hospitalar de Curitiba e teve como objetivo desenvolver dinâmicas educativas junto à equipe de enfermagem no sentido de reorientar as ações para a perspectiva cultural do cuidado de enfermagem à puérpera e seu bebê. Utilizou-se como referencial teórico as idéias e alguns conceitos da Teoria da Diversidade e Universalidade do Cuidado Cultural de Madeleine Leininger. Procurou-se demonstrar a importância do cuidado de enfermagem que revela um compromisso cultural com a puérpera e seu bebê, bem como, a importância das ações educativas reflexivas que buscam o desenvolvimento de profissionais livres e conscientes de si mesmos, envolvidos e decidindo por práticas que incluam suas raízes, sua diversidade, onde o compromisso com a saúde possa ser um resgate de sua cidadania levando-os à atitude de promoção da saúde. O trabalho foi desenvolvido por meio de encontros nos quais eram realizadas dinâmicas educativas em saúde promovendo o desenvolvimento dos valores individuais e coletivos no grupo, com o objetivo de incentivá-los à iniciativa, capacidade de organização, dinamismo, comunicabilidade, liderança, criatividade, à educação em saúde e o compromisso com a efetividade do cuidado cultural de enfermagem como terapêutico e gratificante na obtenção dos resultados esperados. Através de relatos da equipe de enfermagem foi possível detectar o impacto das dinâmicas educativas em saúde a partir da perspectiva cultural do cuidado de enfermagem à puérpera como relevante para a qualidade do cuidado oferecido, assim como a importância do trabalho em grupo favorecendo a aproximação da equipe, motivação e melhoria no relacionamento inter-grupal.

* Enfermeira da Secretaria Municipal de Saúde de Curitiba.

** Enfermeira. Prof. ${ }^{\text {a }}$ Adjunto do Departamento de Enfermagem da UFPR - Sênior. Doutora em Enfermagem - área de concentração Filosofia da Enfermagem. Coordenadora do Núcleo de Estudos, Pesquisa e Extensão em Cuidado Humano de Enfermagem - NEPECHE/UFPR. Orientadora da monografia.
PALAVRAS-CHAVE: Cuidados de enfermagem; Puerpério; Cuidado cultural.

\section{INTRODUÇÃO}

Desde o início de minha formação tenho percebido que a enfermagem deve ser compreendida como ciência e arte do cuidar. Meu interesse pela saúde da mulher iniciou durante o curso de enfermagem, em que observei que o cuidado com as gestantes e puérperas não era integral, havia descontinuidade principalmente quando deixavam as unidades de saúde (US) ou a maternidade. Experienciei na minha caminhada acadêmica que a cultura e o cuidado de enfermagem caminham juntos, que a vida de um indivíduo é marcada por fatores históricos e que ele nasce no seio de uma família e de uma cultura. Com o intuito de realizar o cuidado alicerçado no saber científico utilizando as teorias de enfermagem, abrangendo o período puerperal e o binômio mãe-filho, iniciei o contato com as idéias da Teoria da Diversidade e Universalidade do Cuidado Cultural de Madeleine Leininger para desenvolver o trabalho monográfico de conclusão do Curso de Enfermagem. Identifiquei-me com as bases filosóficas da Teoria de Leininger por entender que 0 enfermeiro(a), bem como a equipe de enfermagem, precisam perceber e respeitar a heterogeneidade cultural do contexto onde atuam, conhecendo, aprendendo e ensinando.

Leininger, referida por POLI (2000, p.17), salienta que "o cuidado de enfermagem benéfico, saudável e satisfatório com base na cultura, contribui para o bem-estar dos indivíduos, das famílias, dos grupos e das comunidades dentro de seus contextos ambientais". Durante a permanência na Unidade de Alojamento Conjunto da instituição hospitalar onde desenvolvi este trabalho pude perceber a necessidade de desvelar os aspectos que permeiam o cuidado cultural. Tornou-se claro que ainda é deficiente a interação, o engajamento e o inter-relacionamento entre os profissionais da equipe de enfermagem que atuam diretamente com as mulheres no puerpério. 
Esse fato pode ser melhor entendido segundo ROSÁRIO (2000), quando descreve que os recursos humanos que atuam na área da saúde apontam descontentamento no trabalho, principalmente quanto aos salários, atribuições em demasia, encargos, dificuldades, fatores atrelados a várias culturas, valores dos próprios profissionais, o que sem dúvida resulta na insatisfação e diminuição da qualidade do cuidado às clientes. O desequilíbrio evidencia-se entre os custos e benefícios do processo de trabalho em enfermagem.

Assim, optei em trabalhar com a abordagem do cuidado cultural junto à equipe de enfermagem na forma de oficinas de educação em saúde, onde além de abordar o cuidado cultural, trabalharia também a motivação e relacionamento inter-grupal através de dinâmicas de grupo com diferentes estratégias metodológicas. Considero as ações educativas como um instrumento de cuidado pois auxiliam as pessoas envolvidas a realizar uma reflexão crítica sobre o processo de saúde-doença, bem como sobre o comportamento de cada indivíduo envolvido no processo de cuidar. A educação em saúde deve ser baseada no diálogo e na troca de saberes. Segundo Meyer apud KOHLRAUSCH; ROSA (1999), as ações educativas reflexivas buscam o desenvolvimento de sujeitos livres e conscientes de si mesmos, envolvidos e decidindo por práticas que incluam suas raízes, sua diversidade, onde o compromisso com a saúde possa ser um resgate de sua cidadania, levando-os à atitude de promoção da saúde.

Para alcançar essas metas, tracei os objetivos que incluem: desenvolver dinâmicas educativas junto à equipe de enfermagem no sentido de reorientar as ações para a perspectiva cultural do cuidado de enfermagem à puérpera $\mathrm{e}$ seu bebê; realizar dinâmicas educativas com a equipe de enfermagem, resgatando a motivação e inter-relacionamento grupal; inserir, através da discussão de técnicas de cuidado à mãe e bebê, a perspectiva cultural no desempenho da equipe de enfermagem; detectar o impacto das dinâmicas educativas junto à equipe de enfermagem, voltadas à perspectiva cultural do cuidado.

\section{REFERENCIAL TEÓRICO}

LEININGER (1985), enfermeira e antropóloga, dedicase ao cuidado cultural da enfermagem desde meados da década de 1950. Elaborou a Teoria da Diversidade e Universalidade do Cuidado Cultural, fundamentada na perspectiva antropológica, na qual o homem tenta compreender e respeitar o homem. A enfermagem, ao atuar nessa perspectiva, estará compreendendo o contexto cultural dos clientes, famílias e comunidades, trabalhando de maneira "co-participante para obtenção de cuidados culturalmente congruentes" (Leininger apud MONTICELLI, 1997, p. 70).

O cuidado de enfermagem deve ser construído a partir de um contexto cultural e desenvolver-se através dele, pois a cultura influencia diretamente o processo saúde-doença dos indivíduos. Cada cultura traz consigo valores, crenças, normas e práticas peculiares da vida cotidiana, que foram aprendidos através da história de vida de cada indivíduo, a qual serve de alicerce aos padrões de comportamento em torno do cuidado humano.

É importante considerar que a introdução do ser humano na cultura acontece na família e é dentro da família, segundo MONTICELLI (1997), que o mesmo adquire e desenvolve significados que posteriormente serão traduzidos em ações e comportamentos durante todo o seu processo de viver. Nesse sentido, o cuidado tanto é desenvolvido pelos profissionais de saúde quanto pelas famílias. Existe uma preocupação bastante grande, principalmente por parte dos enfermeiros que desenvolvem suas práticas assistenciais, em conhecer, considerar e valorizar as crenças, valores e práticas populares de saúde para que o cuidado possa ser compartilhado. A teoria de Leininger possibilita que se obtenha um melhor conhecimento da realidade das pessoas, considerando o meio em que vivem, assim como os grupos, as instituições ou comunidades em que estão inseridas (POLI, 2000).

Considero importante salientar os conceitos propostos por LEININGER (1985, p.261-262) e publicados por GEORGE (1993, p.287-290), pois de forma sucinta demonstra suas idéias envolvendo a Cultura: refere-se aos valores, crenças, normas e modos de vida praticados, que foram aprendidos, compartilhados e transmitidos por grupos em particular que guiam pensamentos, decisões e ações, de forma padronizadas; Valor cultural: refere-se à forma mais desejada ou preferida de agir ou conhecer algo, que é freqüentemente mantida por uma cultura por um período de tempo, e que governa as ações ou decisões das pessoas; Diversidade Cultural do Cuidado: refere-se à variabilidade das ações de assistência, apoio, ou facilitadoras para com outro indivíduo ou grupo, que são decorrentes de uma cultura específica, para melhorar ou amenizar a condição humana de vida; Universalidade Cultural do Cuidado: refere-se aos fenômenos uniformes, ou comumente dirigidos a outro indivíduo ou grupo, que são decorrentes de uma cultura específica, para melhorar ou amenizar a condição humana de vida.

A Teoria de Leininger possibilita a aproximação do cuidado de enfermagem ao cuidado popular, entendendo que "o cuidado é o fenômeno constitutivo básico da existência humana" (Roach apud WOLFF, 1998, p.32) e que, portanto, 
está presente em todos os seres humanos independente se os mesmos exercem um cuidado profissional ou não.

LEININGER (1985, p.261-262) explicita o conceito de Cuidado (substantivo) como fenômenos relacionados com o comportamento de prestação de auxílio, apoio ou capacitação, para um indivíduo ou grupo, com necessidades evidentes ou antecipadas de melhorar ou aperfeiçoar uma condição ou modo vida humanos; e de Cuidar (verbo) quando se refere à ações e atividades de assistência, apoio, ou facilitadoras para com outro indivíduo ou grupo com necessidades evidentes ou antecipadas, para melhorar ou aperfeiçoar uma condição ou modo de vida humanos, ou para enfrentar a morte; LEININGER (1985) define sistema profissional referindo-se aos serviços de cuidado e cura organizados e interdependentes, que vêm sendo identificados com ou oferecidos por vários profissionais da saúde.

WOLFF et al., (1998, p.32) enfatizam que "o cuidado representa a união entre dois seres humanos, construída a partir de suas experiências de vida, oportunidade em que acontecem trocas, aprendizado e desenvolvimento mútuos, exigindo que ambos revelem o seu ser, e resgatem a humanidade existente em cada um".

Desta forma, o cuidado está inserido num contexto cultural, sofrendo influências sócio-econômicas, em que o ser cuidado e o cuidador trocam e sofrem influências. Na visão de Roach apud WOLFF et al. (1998), o cuidado é culturalmente aprendido e a maneira como fomos cuidados ou expressamos cuidado influenciará na nossa maneira de cuidar.

Leininger, citada por POLI (2000, p. 58), explicita três modos de decisões e ações de cuidado de enfermagem, os quais considero necessário salientar para melhor compreensão de suas idéias:

Manutenção ou preservação do cuidado cultural refere-se àquelas ações e decisões profissionais de assistência, apoio e capacitação que ajudam as pessoas de uma determinada cultura a ajustar e/ou preservar valores de cuidado relevantes para que elas possam manter seu bem-estar, recuperar-se de doenças, ou enfrentar a deficiência e/ou a morte;

Acomodação ou negociação do cuidado cultural refere-se àquelas ações e decisões criativas de assistência, apoio, facilitação ou capacitação que ajudam as pessoas de uma designada cultura a adaptarse aos outros ou negociar com eles para que obtenham um resultado benéfico e satisfatório com os provedores de cuidado profissional;

Remodelação ou reestruturação do cuidado cultural refere-se àquelas ações e decisões profissionais de assistência, apoio, facilitação e capacitação que ajudam os clientes a reordenar, mudar, ou modificar acentuadamente seus modos de vida para um modelo de cuidado de saúde novo, diferente, e benéfico enquanto respeita os valores e as crenças culturais e ainda provê um modo de vida mais benéfico e saudável do que antes das mudanças serem co-estabelecidas com os clientes.

A abordagem cultural remete os profissionais de saúde, e particularmente os enfermeiros(as), a entenderem que sua atuação como profissional do cuidado deve compreender a visão de mundo dos seres humanos com quem estão envolvidos na assistência à saúde. Quando falamos em perspectiva cultural do cuidado às puérperas $e$ seus bebês, as ações educativas são de grande valia pois uma grande parte do cuidado de enfermagem oferecido às puérperas está voltado às orientações. $\mathrm{Na}$ atuação do profissional enfermeiro as ações educativas destacam-se pela grande importância que exercem quando bem manejadas na vida da cliente. Assim, os três modos de ações de cuidado de enfermagem são utilizados a cada momento de interação entre profissional e cliente. Para POLI (2000, p.42) "A ação educativa tem sido um cuidar cada vez mais presente na enfermagem. A educação em saúde transcende os ensinamentos de ações corretas sobre como preservar ou adquirir saúde. É necessário possibilitar que as pessoas utilizem suas próprias habilidades e conhecimentos adquiridos a fim de encontrar soluções aos seus problemas e condições para uma tomada de decisão consciente".

Quando o enfermeiro trabalha com a equipe através da reciclagem de determinados assuntos e novas propostas de cuidado, entre outras temáticas, estará desenvolvendo ações educativas junto à equipe, e esta foi a proposta por mim executada durante o estágio na Unidade de Alojamento Conjunto (AC). Nessa Unidade a mulher vivencia o puerpério, o qual pode ser definido, segundo ZIEGEL e CRANLEY (1985), como o período que tem início após o parto e termina quando a fisiologia materna volta ao estado anterior, ou seja, aproximadamente seis semanas depois. Entendo que o puerpério é um período de recuperação fisiológica do organismo da mulher e que cronologicamente é variável, não podendo ser visto como um evento isolado em sua vida. É um momento de grande impacto, confusão e ambigüidade. O período puerperal para SOIFER (1986, p.63) configura-se como uma "...situação de delimitação entre o perdido: a gravidez e o adquirido: o filho. Também de delimitação entre devaneio, fantasia inconsciente e realidade".

Porém sabe-se que no puerpério, apesar de todas as manifestações físicas e emocionais que ocorrem na vida da mulher, muitas vezes o cuidado da sua saúde é negligenciado, sendo a atenção mais voltada para o recémnascido. SILVA (1988, p.237), estabelece que "na sociedade, 
de modo geral, o nascimento de uma criança é motivo de grande alegria e comemorações. No entanto, para a mulher que se torna mãe, este período pode ser marcado por ansiedades e preocupações, principalmente quando se trata do primogênito".

Para GLAT (1994), no puerpério uma certa dicotomia de papéis acompanha a mulher: o ser mulher maternal e o ser mulher sensual. Neste sentido, a mulher se vê obrigada a escolher entre um desses papéis sem se dar conta de que ambas as posturas são complementares e não mutuamente exclusivas. O fato de a mulher colocar de lado sua sensualidade para se dedicar à maternidade faz com que ela esteja perdendo sua maior fonte de prazer. A puérpera sente uma certa dificuldade em entender e administrar a ambigüidade entre suas expectativas sobre maternidade e o cotidiano cansativo dos primeiros meses de um recémnascido. Uma assistência inadequada da equipe de saúde, nesse período de instabilidade emocional, pode dar origem à depressão puerperal ou depressão pós-parto (Beinstein apud SILVA, 1988).

Para Rocha, apud LUIS; OLIVEIRA (1998), com o nascimento de um filho espera-se, em qualquer cultura, que a mulher se torne feliz, mostre-se receptiva com ele e apta ao papel de mãe, sem negligenciar suas funções de esposa, dona de casa e outras inerentes à sua vida social. Exigências essas solicitadas à revelia das alterações hormonais, bioquímicas e hidroeletrolíticas que estão se processando no seu organismo e da necessidade psicológica de estruturar um novo papel. O meio circundante espera que a mulher esteja contente com o evento e que seja "uma boa mãe", não levando em conta as possíveis alterações na relação conjugal e familiar ou se a sua inserção social é deslocada, inclusive, na atividade ou carreira profissional interrompida.

Pela complexidade do período puerperal, a mulher necessita de um cuidado de qualidade que seja culturalmente congruente. $\mathrm{O}$ fato de existirem diferentes práticas de saúde relacionadas com uma rede de significados que as mulheres desenvolvem durante o ciclo gravídico-puerperal, remete a equipe de enfermagem à necessidade de repensar e ampliar o seu papel social, valorizar sua atuação no processo saúdedoença e redimensionar sua cultura profissional. O profissional enfermeiro deve subsidiar suas ações de cuidado em um referencial teórico que avalie o contexto histórico, cultural, social, financeiro e afetivo em que a puérpera e sua família estão inseridos. Valorizando este contexto, o enfermeiro desempenhará as ações de cuidado através da interação profissional, buscando compartilhar significados, crenças, normas e valores com as mulheres e seus recém-nascidos, para juntos, segundo Leininger apud MONTICELLI (1997), preservarem, acomodarem e/ou reorganizarem ações, comportamentos e ritos de saúde relacionados com esse momento especial da vida.

\section{REFERENCIAL METODOLÓGICO}

O fator cultural no processo saúde-doença vem, aos poucos, recebendo mais atenção dos profissionais da área da saúde, pois eles perceberam que não é suficiente prestar cuidados, mas sim, fazer com que os clientes possam utilizarse destes para seu benefício.

Optei pelas dinâmicas educativas em saúde com a finalidade de promover o desenvolvimento dos valores individuais e coletivos da equipe de enfermagem que atua em $A C$, a fim de motivá-los à iniciativa, capacidade de organização, dinamismo, comunicabilidade, liderança e criatividade. Na enfermagem essas necessidades tornam-se claras, uma vez que tem na educação uma forte vertente, seja ela com a cliente, com os familiares ou grupos específicos. Selecionei algumas dinâmicas, como jogo das aparências; lição dos gansos; valorizando as qualidades e bombom, a fim de otimizar o processo de desenvolvimento dos grupos, facilitando a ação do profissional em educação à saúde e na efetividade do cuidado cultural de enfermagem, os quais podem ser considerados como terapêutico e gratificante na obtenção de resultados esperados.

Selecionei, ainda, algumas técnicas de combate ao estresse com a finalidade de prevenir ou auxiliar os profissionais de enfermagem expostos a situações de estresse ocupacional, com vistas a proporcionar-lhes uma melhoria na qualidade de vida, o que irá refletir-se em suas ações, ou seja, em um cuidado mais efetivo.

\section{LOCAL DE REALIZAÇÃO DO ESTUDO}

O estudo realizou-se em uma instituição hospitalar pública de Curitiba-PR, que conta com 165 leitos, distribuídos entre as várias especialidades, atendendo exclusivamente pacientes do Sistema Único de Saúde (SUS). Essa maternidade foi fundada em 1995, sendo que no dia 15/03/ 2000, recebeu o título de Hospital Amigo da Criança. A Unidade de AC é composta de 7 quartos e 7 enfermarias com 2 e 3 leitos, respectivamente, sendo a permanência de 48 horas para puérperas que foram submetidas a parto normal e de 72 horas para as de cesariana. Algumas puérperas excedem este prazo quando seus recém-nascidos necessitam de internamento para tratamento. Sua equipe de enfermagem é composta de 2 enfermeiras, 3 técnicos de enfermagem, 17 auxiliares de enfermagem e 2 estagiárias, a qual desenvolve o cuidado de enfermagem de forma integral, sendo que cada funcionário é responsável, em média, por 3 enfermarias. 


\section{SUJEITOS DO ESTUDO}

Optei em trabalhar com a equipe de enfermagem do AC, pois a cultura é um conceito básico e indispensável na prestação do cuidado à puérpera e seu bebê, e também por considerar importante o relacionamento intergrupal, uma vez que o mesmo sofre desgaste com o tempo e com o estresse gerado pelo trabalho. Para que pudesse caracterizar os sujeitos, formulei um questionário com questões abertas e fechadas, o qual foi respondido pela equipe, após prévia explicação dos objetivos e da garantia do anonimato das informações. A equipe de enfermagem do AC com a qual realizei as dinâmicas educativas foi composta por seis auxiliares de enfermagem, dois técnicos de enfermagem e três estagiárias, sendo uma do curso de ensino médio de administração, uma do curso de auxiliar de enfermagem e uma do curso de graduação em enfermagem. A média de idade da equipe foi de 38 anos, variando entre 18 e 53 anos. Quanto ao estado civil, seis são casadas, uma é viúva, uma é divorciada e três são solteiras.

\section{ASPECTOSÉTICOS}

Após o consentimento favorável do setor de AC, entrei em contato com a equipe de enfermagem informando-lhes sobre os objetivos, finalidade e sigilo na condução do trabalho, anonimato das informações, em cumprimento à Resolução no 196/96 (BRASIL, 1996). Assegurei que suas participações seriam voluntárias e que a qualquer momento poderiam se excluir do estudo quando julgasse necessário. Seus nomes foram substituídos por nomes de flores.

\section{IMPLEMENTAÇÃO DA PROPOSTA: DINÂMICAS EDUCATIVAS EM SAÚDE}

Várias tendências pedagógicas são utilizadas pelo enfermeiro no desempenho das ações educativas, as quais refletem sua visão de mundo, sua vinculação com processos sociais, políticos e históricos, enfim, sua postura frente ao uso do conhecimento e divisão do saber, demonstrando claramente, na ação educativa, sua ideologia (KOHLRAUSCH; ROSA, 1999).

Libâneo apud KOHLRAUSCH; ROSA (1999), explicita que existem duas tendências pedagógicas: a liberal e a progressista. A pedagogia liberal fundamenta-se na idéia de que a escola tem a função de preparar os indivíduos para o desempenho de papéis sociais, conforme as aptidões individuais, justificando o modelo capitalista, pois este defende a liberdade e os interesses individuais. Na pedagogia progressista, aparece a análise crítica das realidades sociais, onde as finalidades sócio-políticas da educação ficam implícitas. Essa pedagogia pressupõe que, a partir de temas geradores, problematizadores, pertencentes ao cotidiano dos clientes, seja alcançado um nível de conscientização que leve à transformação social.

A tendência pedagógica progressista foi a que mais esteve presente no trabalho com a equipe de enfermagem do AC, pois esta se presta para a educação não formal, a qual era o meu objetivo nesses encontros, pois não havia o intuito de "ensinar alguma coisa", mas de discutir o cuidado prestado às puérperas levando em consideração sua cultura. Para proceder aos registros da prática educativa, optei em realizar anotações em um diário de campo, descrevendo os seguintes itens: dia do encontro, tipo de dinâmica, número de participantes, grau de interesse dos participantes, percepções pessoais, motivação e aproveitamento. Não utilizei o gravador em um primeiro momento, sendo utilizado na última fase do trabalho, pois o mesmo causava constrangimento, inibindo as expressões espontâneas das participantes. Os encontros ocorreram no mês de outubro de 2000.

Pelas especificidades da escala de trabalho necessitei repetir as dinâmicas educativas e a temática abordada três vezes, percorrendo todos os turnos. Não foi possível a participação de todos os funcionários, devido à mudança de plantões, equipes que já haviam participado ou equipe reduzida por ausências de pessoal naquele turno.

O primeiro encontro com o grupo A contou com 7 participantes, grupo B com 6 participantes. Não ocorreu o encontro com o grupo $C$, não compareceu nenhum membro da equipe ao encontro, pois se encontravam bastante ocupados devido às muitas trocas de plantões. Apresentei alguns conceitos da teoria do cuidado cultural e discutimos a sua aplicabilidade. A dinâmica realizada foi a do "Jogo das Aparências", que tem como principal objetivo demonstrar como estereótipos e interpretações subjetivas interferem na comunicação. Foi entregue para cada uma das participantes um balão e um pedaço pequeno de papel em branco, em que cada participante escrevia três características pessoais de maneira que a partir dessas características ela pudesse ser identificada pelos outros participantes. Este papel foi colocado dentro do balão o qual foi cheio. Todos os participantes jogaram seus balões para cima ao som de uma música animada e quando a música parou cada participante pegou o balão que estivesse mais próximo e o estourou. Cada um leu o papel que continha dentro dos balões e tentou identificar qual era a pessoa que apresentava as características descritas. As pessoas cujas características foram sendo reveladas se apresentavam ao grupo explicando o porquê das características. O grupo A mostrou-se descontraído, embora alguns participantes estivessem um pouco receosos no início. 
O grupo $\mathrm{B}$ foi menos receptivo à temática abordada e participou menos na dinâmica.

Ao final da realização da dinâmica, surgiram as seguintes colocações:

"Foi bastante interessante...gostei!" (Cravo - Grupo A)

"Isso ajuda a conhecer melhor as pessoas. Coisas que a gente acha que sabia sobre a outra e não é bem assim!" (Margarida - Grupo A)

"É divertido". (Rosa - Grupo A)

"É engraçado falar da gente... mas faz bem para se conhecer." (Girassol - Grupo B)

"Bom pra se conhecer melhor, as vezes não é o que parece." (Violeta - Grupo B)

No segundo encontro a dinâmica utilizada foi "Lição dos Gansos" cujo principal objetivo é vivenciar o espírito de grupo. Os participantes de cada grupo, neste encontro foram divididos em dois subgrupos, e foram distribuídas cópias do texto Lição dos Gansos, o qual fala do comportamento dos gansos em seus bandos. Os subgrupos tiveram um tempo aproximado de sete minutos para refletirem acerca das lições que poderiam ser extraídas de cada item do texto e estabeleceram associações com as relações humanas anotando-as no papel nos espaços destinados. Cada subgrupo leu a folha, discutiu e anotou as conclusões do grupo. Entreguei aos grupos, então, um texto já com as analogias feitas, próprias da dinâmica. Houve uma discussão dos principais pontos abordados e as relações estabelecidas com as analogias: Até que ponto buscam a mesma direção? Que tipo de relacionamentos estabelecem com quem os lideram? O grupo A teve 4 participantes, o B 5 participantes e o C 4 participantes. A temática abordada foi "tópicos sobre amamentação com o enfoque na perspectiva cultural do cuidado". Os grupos A e B estavam bastante receptivos e participativos, enquanto que o grupo $C$, por não ter realizado o primeiro encontro, estava desmotivado, não demonstrava muito interesse e foi pouco participativo. O tema gerou muitas colocações e as participantes puderam expor suas opiniões, as quais, muitas vezes, divergiam da prática imposta pelo hospital, isto é, o saber científico colidindo com o saber popular. Inicialmente a equipe A estava bastante apreensiva sobre o que eu traria para elas nesse encontro:

"O que é que você trouxe hoje para nós? Vai ter bexiga novamente? Foi bastante divertido, isso faz bem..." (Cravo- Grupo A)

"Vamos falar do quê hoje? Vai ter alguma brincadeira? (Margarida - Grupo A)

A dinâmica "Lição dos Gansos" foi impactante para os grupos A e B levando as participantes a avaliarem e refletirem suas posições e atitudes na equipe, o companheirismo e a motivação. Resgataram a questão da cultura individual na prestação do cuidado à puérpera, bem como os mitos, crenças e tabus que são próprios da amamentação, questionando a importância do profissional saber se colocar perante a cliente fazendo com que esta possa acreditar no cuidado e nas informações prestadas, como pode ser visto a seguir:

"Sabe, é muito bom a gente falar dessas coisas, de vez em quando a gente tem que parar e discutir algumas coisas erradas da equipe, como hoje foi feito, porque se não for feito vai virando uma bola de neve e depois não tem jeito". (Cravo - Grupo A)

"É muito importante discutir com a equipe a forma como a gente está agindo uma com a outra, temos que trabalhar unidas, e estar ajudando uma a outra, como diz ali nos gansos. Isso é muito importante, pois às vezes a gente tá com problemas em casa e aqui no hospital a gente não consegue render igual, então é muito bom ter uma amiga que entenda e te ajude!". (Margarida - Grupo A)

"Essa questão da cultura é bem importante, principalmente na amamentação onde sempre tem alguém da família dando palpite". (Begônia - Grupo B)

"A gente tem que adquirir a confiança da paciente prá ela acreditar que o que a gente está falando está certo, por isso que é importante saber se o que ela sabe sobre a amamentação tá certo ou errado. E também não dá prá chegar mandando, às vezes já é o quinto, sexto filho e ela sempre fez daquele jeito, quem sou eu pra dizer o contrário, se não fizer mal, então..." (Dália Grupo B)

"Seria muito bom se a gente trabalhasse como os gansos, pena que não é bem assim..." (Copo-de-leite Grupo C)

"Com tanto trabalho a gente tem que fazer o que dá e pronto, nem dá pra pensar muito." (Jasmim - Grupo C)

Com relação ao grupo $\mathrm{C}$, percebi que este grupo parecia não ter entendido a importância deste trabalho para mim e que elas também não entenderam a importância do mesmo para elas. Nas semanas seguintes cheguei à conclusão de que não havia mais possibilidade de continuar as reuniões com o grupo $\mathrm{C}$, mas mesmo assim, sempre havia alguém deste grupo participando nas outras equipes devido às muitas trocas de plantões.

No terceiro encontro discutimos a técnica do banho do RN na perspectiva cultural do cuidado e a dinâmica realizada foi "Valorizando as Qualidades". Apenas os grupos A e B participaram, cada um com seis participantes. A 
dinâmica tem como principais objetivos identificar aspectos qualitativos das pessoas envolvidas por meio da observação e promover a auto-estima. Foi entregue para cada participante uma folha de papel em branco e o grupo formou um círculo onde todos podiam observar os outros. Foi feito um comentário que no cotidiano as pessoas têm a tendência de observar com mais rigor os defeitos e menos as qualidades das pessoas com as quais se relacionam. Solicitou-se que observassem os colegas e que cada um colocasse seu nome na folha e em seguida a folha foi passada para a pessoa à direita o qual colocava uma ou mais qualidades do colega, identificando-se ou não. Depois a folha foi sendo dobrada (tipo sanfona) e passada adiante para a próxima pessoa à direita, repetindo o processo até que a folha chegasse ao seu dono. Ao final cada participante pôde ler suas qualidades o que gerou surpresas positivas, estreitando inclusive os relacionamentos e favorecendo a auto-estima. Questionamos a necessidade de padronização da técnica pela equipe, pois muitas profissionais a realizam de diferentes formas gerando dúvidas nas puérperas, bem como a necessidade de uma abordagem prévia à puérpera quando deve ser levado em consideração seus conhecimentos anteriores, sua cultura, suas crenças. $O$ grupo $A$ teve grande participação.

"A gente não pode chegar dizendo assim: olha aqui mãezinha porque agora eu vou ensinar você a dar banho no teu bebê. Você já pensou se é o quinto filho dela, quem disse que ela não sabe dar banho?" (Cravo Grupo A)

"A gente tem que fazer a técnica do banho de forma que elas vão fazer igual em casa, se não elas chegam em casa e fazem tudo diferente e daí não adianta nada. O melhor é saber o que elas já sabem e tentar fazer mais ou menos do jeito delas. Claro que se tiver muito errado, a gente tem que corrigir só que falando com jeitinho..." (Tulipa - Grupo A)

"Eu acho que todas nós deveríamos ensinar o banho do bebê mais ou menos na mesma técnica, se não a gente dá um nó na cabeça delas". (Margarida - Grupo A)

"Seria bom que a gente fizesse tudo seguindo um técnica igual e ao mesmo tempo respeitando e aproveitando o que a mãe já sabe, com certeza ficaria bem melhor." (Girassol - Grupo B)

"Essa questão de cultura é mesmo muito importante até no banho que parece algo tão banal..." (Dália Grupo B)

Com relação à dinâmica, o grupo $A$ teve bom aproveitamento, resgatando alguns valores pessoais, o que foi muito importante para o grupo. Observei que elas sentiramse mais motivadas em realizar suas atividades. O grupo B recebeu muito bem a dinâmica, considerando importante resgatar seus valores.

"É tão bom saber as nossas qualidades. Hoje em dia as pessoas só apontam nossos defeitos. Vou até trabalhar melhor hoje". (Margarida - Grupo A)

"Acho bom saber o que as pessoas pensam de mim, faz bem para o ego da gente!". (Cravo - grupo A)

"Sabe que é muito bom você aqui, você sempre traz coisas novas, a gente precisa sair dessa mesmice. Estou achando muito legal esse teu trabalho com a gente. Espero que se uma outra amiga tua vier aqui também traga coisas novas". (Violeta - Grupo B)

"No fundo a gente já sabe o que tem que fazer, mas de vez em quando é bom a gente reavaliar nossas atitudes e mudar aquilo que não estamos fazendo direito." (Dália - Grupo B)

O último encontro abordou as modificações do organismo feminino no puerpério com o enfoque na perspectiva cultural do cuidado e a dinâmica realizada foi a do "Bombom" que tem como principal objetivo fortalecer a auto-estima através do enaltecimento das qualidades do indivíduo. Foi solicitado que cada participante escolhesse um ou mais bombons da caixa e que o entregasse a um outro integrante do grupo explicando o porquê da escolha: por afinidade, reconciliação, por tentativa de aproximação ou outro motivo. A pessoa que recebeu o bombom realizou o mesmo processo dando continuidade à dinâmica. Os grupos reagiram bem à dinâmica demonstrando satisfação e contentamento como pode ser observado nas seguintes falas:

"Além de receber um bombom prá adoçar a vida a gente ainda recebe elogios!" (Tulipa - Grupo A)

“É bom prá ver se a gente consegue ficar mais unida, sem contar, é claro, com um bombom que é muito gostoso! (Begônia - Grupo B).

Nesse encontro encerraram-se as atividades com a equipe de enfermagem, momento em que agradeci a disponibilidade e a participação de todos, ressaltando o quanto havia sido importante compartilhar idéias, os conhecimentos, as experiências e a convivência grupal. Para melhor registrar suas percepções a respeito de todo o trabalho de desenvolvimento das dinâmicas educativas, ocorridas nos diferentes encontros com os três grupos, formulei um instrumento composto de cinco questões abertas, que enfocavam suas percepções e avaliações. Utilizou-se um mini-gravador. As questões foram respondidas por 6 participantes do estudo, uma vez que as outras cinco optaram em não responder o questionário. Cito algumas das respostas obtidas: 
"Eu procuro aplicar os conceitos aprendidos, respeitando a cultura das pacientes". (Rosa - Grupo A)

"A gente tem que respeitar aquilo que a pessoa já sabe". (Margarida - Grupo A)

"A gente tem que se fazer entender pelas pacientes, entrar na cultura." (Girassol - Grupo B)

"Eu tô procurando melhorar, não adianta falar muito numa linguagem que a mãe não entenda, é melhor falar menos e ela entender e buscar saber o que ela já sabe porque às vezes é até melhor pra gente". (Cravo - Grupo A)

"Teve sucesso porque muitas não respeitavam a cultura da paciente e agora tentam fazer diferente". (Rosa Grupo A)

"Pena que não deu muito certo o nosso grupo mas eu acredito que se a gente entender um pouco mais essa questão da cultura das nossas pacientes a gente pode cuidar bem melhor e fazer com que elas fiquem mais satisfeitas". (Copo-de-leite - Grupo C)

De acordo com esses depoimentos percebe-se a importância que a equipe atribuiu à cultura das puérperas, mostrando a necessidade de desvendar os conhecimentos, crenças e valores das clientes para que, desta forma, ocorram trocas de conhecimento popular e profissional. O cuidado cultural, então entendido pela equipe de enfermagem, demonstrou a importância de serem desenvolvidos cuidados que sejam culturalmente congruentes, desempenhando seus papéis de acordo com suas próprias expectativas e também com as expectativas das puérperas, procurando a manutenção, acomodação ou reorganização dos cuidados desenvolvidos durante o puerpério.

A equipe foi unânime em responder que existe aplicabilidade dos conceitos discutidos, e que esta aplicabilidade se dá principalmente nas palestras sobre o aleitamento materno realizadas na Unidade de AC, momento em que as puérperas podem expor suas dúvidas, crenças e valores oportunizando socializar os conhecimentos e detectar os mitos e tabus que podem interferir no cuidado de qualidade. Para a equipe esse é um momento muito importante, onde podem atuar respeitando a cultura das clientes e ao mesmo tempo trabalhando com o modelo proposto por Leininger: manutenção ou preservação, acomodação ou negociação e remodelação ou reestruturação do cuidado cultural.

Houve também demonstrações negativas do aproveitamento dos encontros:

"Os conceitos até são aplicáveis mas,na prática, não é bem assim..." (Girassol - grupo B)

"É...até que foi importante, mas sei lá..." (Violeta Grupo B)
"A gente discute, a gente fala, mas não é bem assim". (Begônia - Grupo B)

"Falta tempo e motivação, nem tudo é tão bom como deveria." (Copo-de-leite - Grupo C)

Em relação ao relacionamento intergrupal, muitos aspectos positivos foram enfatizados e a equipe demonstrou bastante aceitação e aproveitamento.

"Ajuda a entender as colegas. Você se valoriza porque descobre a forma como elas te enxergam, e também dá oportunidade de saber o que a gente faz de errado e tentar consertar". (Margarida - Grupo A)

"As atividades foram ótimas, é legal para se conhecer melhor, saber entender as atitudes de algumas". (Girassol - Grupo B)

"Espero que todas que passarem pela maternidade façam isso que você fez com a gente porque é bom. Fica assim um ambiente alegre, descontraído, a gente pode falar alguma coisa no papel ou em palavras...Como eu disse pra você, que no começo eu achava você uma chata e hoje eu já tenho uma outra visão tua e isso vem do conhecimento e da convivência, a gente vai aprendendo a conhecer as pessoas e como você falou a gente não pode julgar ninguém antes de conhecer, mas agora eu adoro você." (Cravo - Grupo A)

"Acho que é muito importante e já é um começo, mesmo que ainda tenha muita coisa pra mudar." (Crisântemo Grupo C)

Surgiram também nos encontros algumas dificuldades enfrentadas pelo grupo no que diz respeito às relações de trabalho. Assim foi possível viver as diferenças e divergências sem que isso significasse ruptura ou desagregação, pois, de acordo com Mailihot apud SAEKI et al (1999, p. 345), o ser humano, qualquer que seja seu grau de socialização, deve libertar-se desta falsa obsessão de que só aqueles que nos parecem semelhantes nos são próximos e que para serem fraternais conosco, os outros devem ser idênticos a nós.

"Eu vou dizer pra você que o teu trabalho é ótimo, só que teve dias que eu não gostei, às vezes é até melhor nem saber quem não te gosta". (Violeta - Grupo B)

Pôde ser detectada nas falas das participantes a cultura pessoal que antecede a sua formação profissional. Segundo POLI (2000), o cuidado culturalmente congruente permite ao enfermeiro refletir sobre suas próprias ações, valores, crenças e conceitos, muitas vezes sedimentados e esquecidos em sua prática profissional.

"Cada um tem a sua crença e o seu jeito de ser que aprendeu com a mãe, com a avó... Eu também fui assim. Então eu procuro ajudar a mudar a cabeça delas 
prá algumas coisas de hoje que não é como era antigamente como no tempo da avó, mas também tem que respeitar a opinião delas". (Dália - Grupo B)

"Às vezes os conhecimentos modernos são piores do que os de antigamente, e os de antigamente corresponde mais a nossa realidade. Nós da área da saúde temos que trabalhar todas as idéias e aplicar o que corresponde melhor no momento. Nós também aprendemos muitas coisas nas nossas casas e que também podem ser usados no trabalho". (Margarida Grupo A)

"Dar liberdade para a paciente desde que não interfira na sua saúde e do bebê, isso para mim é cuidado cultural". (Girassol- Grupo B)

"Dá prá perceber que muita coisa que elas acreditam que é certo eu também acreditava e a gente pode fazer com que isso nos aproxime e a gente possa ensinar aquilo que elas não sabem. (Crisântemo - Grupo C)

O trabalho em grupo foi de grande valor para minha formação profissional, pois compreendi melhor o processo educativo e a necessidade de valorizar o indivíduo, o qual possui experiências e saberes anteriores, adquiridos em sua vivência profissional, que não podem ser desprezados. As necessidades profissionais devem ser satisfeitas e as potencialidades pessoais devem ser desenvolvidas, tornandose necessário que a aprendizagem seja significativa para o aprendiz, envolvendo-o como pessoa, como um todo.

\section{CONSIDERAÇÕES FINAIS}

Considerando o saber científico como instrumento do crescimento e desenvolvimento profissional, onde se busca subsídios para a prática diária, é necessário entender que, na enfermagem, como na maioria das áreas do saber, essas práticas requerem atualização constante e aperfeiçoamento do relacionamento interpessoal, entre profissional e cliente, para que este profissional deixe de ser transmissor para ser um agente transformador da realidade junto à comunidade.

A realização deste trabalho trouxe a oportunidade de vivenciar as dificuldades e as possibilidades concretas da realização de um trabalho coletivo. Viver o grupo significa lidar com a diversidade, com a falta de algo pronto e acabado, com a possibilidade do conflito e do confronto, mas também, com a união e a criação (SAEKI et al., 1999).

Desta forma, compreendi que o trabalho em grupo requer do profissional enfermeiro um maior entendimento do processo de educação em saúde, pois as ações educativas em saúde constituem-se num dos instrumentos mais utilizados pela enfermagem. As ações educativas voltadas para o desenvolvimento pessoal e profissional apresentam grande relevância uma vez que se trabalha a valorização de conquistas no cotidiano dos serviços de saúde, enfatizando o desenvolvimento dos profissionais como sujeitos autônomos, e que, segundo LIMA (1996), essa autonomia é construída com base na transformação de sua vida profissional em algo mais rico e inovador, elaborando propostas de reorganização do trabalho.

Essa transformação da vida profissional e a reorganização do trabalho individual da equipe de enfermagem do AC foi por mim almejada, uma vez que me propus trabalhar a perspectiva cultural do cuidado através da discussão de temas pertinentes ao cuidado de enfermagem prestado à puérpera e ao seu bebê, usando as dinâmicas educativas.

Estou convicta de que trabalhar com as idéias e alguns conceitos da Teoria da Diversidade e Universalidade do Cuidado Cultural de Leininger foi bastante interessante, enriquecedor e estimulante. A prática profissional deve estar alicerçada num conhecimento que seja capaz de superar as barreiras encontradas e vivenciadas no cuidado à puérpera e seu bebê, para que o profissional e a cliente possam desfrutar de um cuidado que seja culturalmente congruente e satisfatório para ambos. Para POLI (2000), o cuidado cultural revela uma rede de significados que compõem a cultura e o contexto das relações que se estabelecem durante o puerpério.

A enfermagem deve buscar uma participação ativa das puérperas, valorizando seus saberes, aproveitando a riqueza da interação enfermagem-cliente para uma maior intimidade com as diferentes visões de mundo e com as diversas redes de símbolos e significados que são partes indissociáveis de nossa cultura. Também acredito ser de grande importância uma atualização e reorganização do papel do enfermeiro como educador, estimulando os co-participantes do processo de cuidar no puerpério, isto é, a equipe de enfermagem e as puérperas, a expressarem seus sentimentos, suas crenças, seus valores, possibilitando condições para que nós também estejamos aprendendo com eles sobre nós mesmos.

ABSTRACT: This study was held in a hospital in Curitiba in order to reorient actions under a cultural care focus on mothers and their newly-born babies. The theoretical background was founded on the ideas as well as some concepts of Madeleine Leininger's Cultural Care Universality and Diversity Theory in order to reach this goal. The work was effected through meetings and educational health dynamics. They aimed to promote individual and group values and help nursing professionals' education towards the development of their initiative, organization skills, liveliness, comunicability, leadership, creativity, health education and cultural care effectiveness. It was possible to evidence, from the staff 
accounts, the impact of educational health dynamics, proving the relevance of the cultural focus on the quality of the nursing care provided to mothers at puerperium and their babies. It was also evidenced the importance of team work which brings about the team union, motivation and improvement on professional intergroup performance.

KEY WORDS: Nursing care; Puerperium; Cultural care.

\section{REFERÊNCIAS}

1 BOEHS, A.E. Que poder a enfermeira utiliza na abordagem cultural à família? Rev. Enferm. UERJ. Rio de Janeiro, v.7, n.1, p.61-67, jan./jun. 1999

2 BRASIL, Ministério da Saúde. Conselho Nacional de Saúde. Resolução $n^{\circ} 196$, de 10 de outubro de 1996. trata das diretrizes e normas regulamentadoras de pesquisa envolvendo seres humanos. Brasília, 1996.

3 GEORGE, J.B.; et al. Teorias de enfermagem: os fundamentos para a prática profissional. Porto Alegre: Artes Médicas, 1993.

4 GLAT, R. Ser mãe, e a vida continua. 2.ed. Rio de Janeiro: Agir, 1994.

5 KOHLRAUSCH, E.; ROSA, N.G. Relacionando os modelos assistenciais e as tendências pedagógicas em saúde: subsídios para a ação educativa da enfermeira. Rev. Gaúcha Enferm., Porto Alegre, v.20, n. esp., p.113-122, 1999.

6 LEININGER, M. Teoria do cuidado transcultural: diversidade e universalidade. In: SIMPÓSIO BRASILEIRO DE TEORIAS DE ENFERMAGEM. (1.,1985, Florianópolis). Anais. Florianópolis, UFSC,1985 p.255-276.

7 LIMA, M.A.D.S. Educação em saúde: algumas reflexões e implicações para a prática de enfermagem. Rev. Gaúcha. Enferm., Porto Alegre, v.17, n.2, p.87-91, jul.1996.
8 LUIS, M.A.V.; OLIVEIRA, E.R de. Transtornos mentais na gravidez, parto e puerpério, na região de Ribeirão Preto-SP-Brasil. Rev. Esc. Enf. USP, São Paulo, v.32, n.4, p. 314-324, dez. 1998.

9 MONTICELLI, M. Nascimento como um rito de passagem: abordagem para o cuidado às mulheres e recém-nascidos. São Paulo: Robe Editorial, 1997.

10 POLI, L.M.C. O processo do aleitamento materno na perspectiva do cuidado cultural de enfermagem. Florianópolis, 2000. Dissertação (Mestrado em Enfermagem) - Universidade Federal de Santa Catarina.

11 ROSÁRIO, P. S. do. Proposta de cuidar com enfoque educativo às mães em aleitamento materno. Curitiba, 2000. Monografia (Especialização em Projetos Assistenciais) - Universidade Federal do Paraná.

12 SAEKI, T.; et al. Reflexões sobre o ensino de dinâmica de grupo para alunos de graduação em enfermagem. Rev. Esc. Enf. USP, v.33, n.4, p. 342-347, dez. 1999.

13 SILVA, I.A. Reações emocionais da mulher no puerpério. Rev. Esc. Enf. USP, São Paulo,v.22, n.2, p. 237-246, ago.1988.

14 SOIFER, R. Psicologia da gravidez, parto e puerpério. Porto Alegre: Artes Médicas, 1986.

15 WOLFF, L.D.G.; GONÇALVES, L.S.; YEDE, S.B. Cuidar/Cuidado: elementos e dimensões na perspectiva de pessoas internadas em hospital de ensino. Cogitare Enferm. Curitiba, v.3, n.1, p.32-39, jan./jun.1998.

16 ZIEGEL, E.E.; CRANLEY, M.S. Enfermagem obstétrica. 8.ed. Rio de Janeiro: Guanabara Koogan, 1985.
Endereço da autora: Rua Bruno Filgueira, 384 - ap. 211 - Batel 80240-220 - Curitiba - PR E-mail: ivetesanzag@zipmail.com.br 